\title{
Platin ve Bakır Temelli $N$-Heterosiklik Karben (NHC) Komplekslerinin Antikanser Özellikleri ve Etki Mekanizmaları
}

\author{
Aydın AKTAŞ* \\ Inönü Üniversitesi, Fen Edebiyat Fakültesi, Kimya Bölümü, 44280, Malatya, Türkiye \\ (ORCID: 0000-0001-8496-6782)
}

\begin{abstract}
$\ddot{O} z$
Metal- $N$-heterosiklik karben (M-NHC) kompleksleri uzun yıllardır organometalik kimyada katalitik aktivite gösteren bileşikler olarak ön plana çıkmaktadırlar. Son yıllarda bu bileşiklerin biyolojik özelliklerini ön plana çıkaran çalışmalar yoğun ilgi görmektedir. Kanser çağımızın önemli bir hastalığı olup tedavisinde kullanılacak ilaçların keşfi oldukça önemlidir. Bu nedenle M-NHC komplekslerinin antikanser özellikleri ile ilgili çalışmalar önem kazanmıştır. Antikanser etki gösteren platin ve bakır temelli M-NHC kompleksleri, bu komplekslerin en önemli olanlarındandır. NHC'lere bağlı bulunan sübstitüentlerin değiştirilmesi ile M-NHC komplekslerinin antikanser aktiviteleride değişmektedir. Bu bileşiklerin antikanser etki mekanizmaları DNA mutasyonları ve Reaktif Oksijen Türleri (ROT)'nden oluşur. Bununla beraber M-NHC komplekslerinin antikanser etki mekanizmalarını tam olarak ortaya koyacak ve yeni sentezlenecek komplekslere yol gösterecek çalışmalara ihtiyaç vardir.
\end{abstract}

Anahtar kelimeler: N-heterosiklik karben, Metal-NHC kompleksleri, Antikanser ajan, DNA mutasyonu, Reaktif oksijen türleri.

\section{Platinum and Copper Based $N$-Heterocyclic Carbene (NHC) Complexes as Anticancer Properties and Mechanisms of Effect}

\begin{abstract}
Metal-NHC (M-NHC) complexes have been used as the compounds that show catalytic activity for organometallic chemistry at a long time. In recent years, the studies that emphasize the biological properties of these compounds have attracted great interest. Cancer is an important disease of our age and the discovery of drugs to be used in its treatment is very important. Therefore, studies on anticancer properties of M-NHC complexes have important. Platinum and copper-based M-NHC complexes that show the anti-carcinogenic effect are the most important of these complexes. Furthermore, changing of the substituents attached to NHCs changes the anti-carcinogenic activities of the M-NHC complexes. The anti-carcinogenic mechanisms of these compounds occur from DNA mutation and Reactive Oxygen Species (ROS). Also, there is a need for studies that will fully reveal the anticancer action mechanisms of M-NHC complexes and lead to new complexes to be synthesized.
\end{abstract}

Keywords: N-heterocyclic carbene, Metal-NHC complexes, Anticancer agent, DNA mutation, Reactive oxygen species.

\section{Giriş}

Değerlik kabuğunda sadece altı elektron bulunduran, iki komşu gruba kovalent bağ ile bağlı bulunan nötral karbon türlerine karben denir. 1960'lardan önce karben kimyasını araştırmak ve çok reaktif olduğu düşüncesini bertaraf etmek için yoğun çabalar gösterilmiştir. Ancak, bu ligandların kullanıldığ1 M-NHC kompekslerinin kararlı olmalarından dolayı NHC'ler 40 yıla yakın bir süre M-NHC komplekslerinin gölgesinde kalmıştır [1]. Özellikle organik sentezlerde yaygın olarak kullanılan karbenler son derece reaktif ve kısa ömürlü organik türlerdir [2]. İlk olarak 1960'ların başında Wanzlick,

"Sorumlu yazar: aydinaktash@hotmail.com

Geliş Tarihi:07.11.2018, Kabul Tarihi: 24.04.2019 
en önemli singlet karbenler arasında yer alan diazol halkaları üzerinde çalışmaya başlamış ve NHC'ler ile entetraaminler arasında bir dengenin olabileceğini öne sürmüştür. Fakat serbest karben elde edemediğinden bunu kanıtlayamamıştır. Kısa bir süre sonra metal kompleksler için ligant olarak NHC'lerin ilk uygulamaları Öfele [1] ve Wanzlick [3] tarafından bağımsız olarak 1968'de açıklanmıştır.

Geçiş metal kimyasında ligant olarak NHC'lerin önemi 1991'e kadar hızla büyüyen bir araştırma alanı olmuştur. Arduengo tarafından NHC kristallerinin izolasyonu, depolanabilirliği ve aşırı kararlılığ üzerine bir çalışma yayınlamıştır [4]. Arduengo 1991 yılından sonra serbest karbenlerle ilgili çalışmalarını azotlu halkalara uygulamış ve bu tür karbenlere $N$-heterosiklik karben (NHC) adı verilmiştir. İlerleyen yıllarda kararlı NHC'ler ve asiklik karbenler gibi kararlı karbenler ile ilgili heyecan verici çalışmalar yayınlanacaktır. Özellikle M-NHC komplekslerinin katalitik aktiviteleri önemli bir çalışma alanı olmuştur [5-8]. Bununla beraber son yıllarda biyolojik özellikleri ile ilgili gerçekleştirilen çalışmalar da yoğun ilgi görmektedir $[9,10]$.

$N$-heterosiklik karbenler, singlet temel halde bulunan ve içerisinde azot atomu bulunduran heterosiklik türlerdir. Güçlü $\sigma$-donör ve zayıf $\pi$-akseptör özelliği sayesinde neredeyse bütün geçiş metalleriyle bağ oluşturabilmektedirler [4, 11]. Bu özellikleri sayesinde NHC'ler koordine olduğu metal ile güçlü bir etkileşime girerek metal merkezinden kolaylıkla dissossiye olmazlar. Azot atomları üzerinde bulunan ortaklanmamış elektronlar $\pi$ bağ 1 yolu ile karben karbonuna iletilirken, metal atomu $\pi$-geri bağlanması ile M-NHC bağının güçlenmesine katkıda bulunur [12]. Ayrıca fonksiyonel gruplardaki değişim (özellikle de azot atomunun bağlı bulunan gruplar) $N$-heterosiklik karbenlere elektronik ve sterik ayarlanabilirlik gibi eşsiz özellik katmaktadır [13]. NHC'lerde metal-ligand bağının kuvvetli olması ve elektron yoğunluğunun fazla olması nedeniyle M-NHC komplekslerinin katalitik aktiviteleri dikkat çekmektedir. Bununla beraber hazırlanan M-NHC komplekslerinde sübstitüentlerin çeşitlendirilebilir olması, M-NHC yapısının sübstitüentlerin yalnız başına gösterdikleri özellikleri kısıtlamaması, bu komplekslerin biyolojik özelliklerinin de çalışılması gerektiğini ortaya koymuştur. Son zamanlarda M-NHC komplekslerinin antikanser [14, 15], antimikrobial [16], antioksidan [17], antitimör [18] ve antifungal [19] gibi biyolojik aktiviteleri ile ilgili çok sayıda çalışmalar gerçekleşmiştir. Ayrıca kararlı NHC öncüllerinin son zamanlarda enzim inhibisyon etkileri üzerine de çalışmalar bulunmaktadır [20-24].

Günümüzde bilim adamlarının üzerinde en çok çalışma yaptıkları konulardan biri de kanser tedavisi üzerine gerçekleştirilen çalışmalardır. M-NHC komplekslerinin antikanser etkileri de deneylerle ispatlanmıştır. Platin $(\mathrm{Pt})$ ve bakır $(\mathrm{Cu})$ başta olmak üzere birçok metalin, NHC ligandları ile oluşturdukları bileşiklerin antikanser özellikleri keşfedilmiştir. Bu çalışmada Pt ve Cu metallerinin NHC ligantları ile oluşturdukları M-NHC komplekslerinin antikanser özellikleri araştırılmıştır.

\section{Bulgular ve Tartışma}

\subsection{M-NHC komplekslerinin antikanser özellikleri}

\subsubsection{Pt-NHC kompleksleri}

Rosenberg ve arkadaşları tarafından keşfedilen ve antikanser ajan olarak kullanılan cis-platin ya da diğer adıyla cis-diamindikloroplatinyum(II) (DDP), metal temelli bir ilacın ilk başarılı tarihsel örneği kabul edilmektedir [25]. Ayrıca cis-platin'in yanı sıra, karboplatin, oksaliplatin, nedaplatin ve lobaplatin gibi birkaç platin kompleksinin de tümör tedavisinde etkili olduğu kabul edilmektedir (Şekil 1) [26-30]. Ancak sınırlı sayıda tümörün, platin temelli antikanser ilaçlarıyla tedavi edilebileceği bir gerçektir. Bununla birlikte, uygulama alanı olan platin temelli bu ilaçların ciddi yan etkileri (Gastrointestinal ve hematolojik toksisite gibi) [31,32] ve suda düşük çözünürlüğü nedeniyle kullanımı sınırlıdır. Ayrıca bazı tümörler, platin temelli ilaçlara doğal dirençli olabilir veya bazı tümörler DDP tedavi sırasında direnç geliştirebilir [26-28, 33]. Bu dezavantajların üstesinden gelmek için, metal temelli yeni ilaçların geliştirilmesinde, gelişmiş organik ligandları içeren geçiş metal komplekslerinin sentezine giderek daha fazla ilgi duyulmuştur [27, 29, 33-35]. 
<smiles>N[P+](N)(Cl)Cl</smiles>

Cisplatin<smiles></smiles>

Carboplatin<smiles>O=C1O[P]2([NH2+][NH2+]C3CCCCC32)OC1=O</smiles>

Oxaplatin<smiles>CC1O[PH](N)(N)CC1CN</smiles>

Lobaplatin<smiles>N[P+]1(N)OCC(=O)O1</smiles>

Nedaplatin

Şekil 1. İlk Olarak Keşfedilen Platin Temelli İlaçları

M-NHC kompleksleri ilaç olarak kullanıldığında, hücredeki çeşitli organelleri potansiyel olarak uyarabilir [36]. Pt temelli ilaçların aktivitesinin, DNA'nın yanı sıra alternatif bazı bölgeleri etkileyip etkilemeyeceği önemlidir. Bunun tespit edilmesiyle dirençli tümörler tedavi edilebilir. Yakın zamanda, platin(II)NHC komplekslerinin mitokondriyi hedeflediğini ve ardından çeşitli mekanizmalar yoluyla (reaktif oksijen türlerini (ROT) üretmek gibi) hücre apoptozunu indüklediğini gösteren çalışmalar yayınlanmıştır [37-39].

Son yıllarda diğer platin temelli ilaçların yan etkilerinden dolayı, platin-NHC kompleksleri yoğun ilgi görmektedir. Yapılan çalışmada 1 no'lu Pt-NHC kompleksinin serbest -SH (tiyol) grubu içeren peptit yapılarına ve DNA'ya bağlandığı ortaya konulmuştur. Ayrıca yapılan biyolojik aktivite çalışmalarında ksatin benzimidazol ve imidazol türevli NHC ligantlarının farklı özellikte oldukları ortaya konulmuştur [40]. Geleneksel platin temelli ilaçlar DNA'nın küçük oyuklarına kovalent bağla çapraz bağ oluşturarak (özellikle guanin ile bağlanıp) antikanser aktivite gösterirler. 2a-d ve 3a-d PtNHC komplekslerinin düzlemsel konfigürasyon nedeniyle, $\pi-\pi$ istiflenme içeren DNA ile etkileşerek antikanser aktivite gösterdiği ortaya konmuştur [41].<smiles>CC(C)(C)NC1NNC(NC(C)(C)C)P1(Cl)(Cl)Cl</smiles>

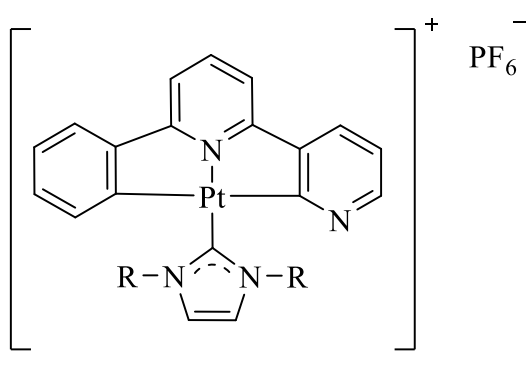

2a $\mathrm{R}=n$ - $\mathrm{Bu}$

2b $\mathrm{R}=\mathrm{Pr}$

2c $\mathrm{R}=\mathrm{Et}$

2d $\mathrm{R}=\mathrm{Me}$

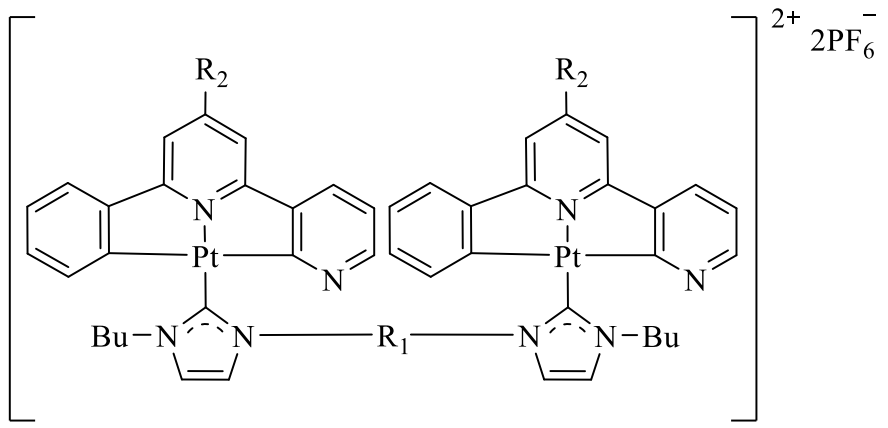

3a $\mathrm{R}_{1}=-\mathrm{CH}_{2}-\mathrm{CH}_{2}-\mathrm{CH}_{2}-\quad ; \mathrm{R}_{2}=\mathrm{H}$

3b $\mathrm{R}_{1}=-\mathrm{CH}_{2^{-}} \quad ; \mathrm{R}_{2}=\mathrm{H}$

3c $\mathrm{R}_{1}=-\mathrm{CH}_{2^{-}} \quad ; \mathrm{R}_{2}=\mathrm{Ph}$

3d $\mathrm{R}_{1}=-\mathrm{CH}_{2^{-}} \quad ; \mathrm{R}_{2}=3,5^{\mathrm{r}} \mathrm{Bu}_{2} \mathrm{Ph}$ 
Ayrıca, farklı bir çalışmada SK-OV-3 hücrelerine karşı cis-platin için $6,1 \mu \mathrm{M}$ olan $\mathrm{IC}_{50}$ değeri 4 ve 5 kompleksleri için $2.8 \mu \mathrm{M}$ ve $2.6 \mu \mathrm{M}$ olduğu tespit edilmiştir. Bu sonuçlar $\mathbf{4}$ ve $\mathbf{5}$ komplekslerinin cisplatin'den önemli ölçüde daha etkili olduğunu göstermektedir [39].<smiles></smiles>

4<smiles>CN1C=CN(Cc2ccc(C(F)(F)F)cc2)C1[I+](I)(I)NC1CCCCC1</smiles>

5

Bouché ve arkadaşları, sentezledikleri Pt(IV)NHC komplekslerinin HCT116, MCF7 ve PC3 insan kanser hücrelerine karşı aktivitelerini incelemişlerdir. Çalışmalarında Pt(IV) bileşiklerinin sitotoksik aktivitesinin mitokondriyal fonksiyon bozukluklarıyla ilişkili olup olmadığını araştırmak ve mitokondrideki ROT üretimini değerlendirmek için Pt(IV)NHC kompleksleri $\mathbf{6}$ ve 7 ile çalışmışlardır [42]. Böylece hem ROT üretimi hem de mitokondrinin normal solunum aktivitesindeki azalmay1 araştırmışlardır. Genellikle Pt(II)oksaliplatin kullanılarak tedavi edilen kanser hücreleri HCT116 üzerindeki etkileri incelendiğinde, Pt(IV)NHC kompleksleri 6 ve 7, ROT üretimini indüklediği bilinen ve bir referans olarak kullanılan staurosporine [43] benzer, oksaliplatin'den daha yüksek bir ROT üretimi göstermiştir [42]. İnsan kanser hücreleri HCT116 için $\mathrm{IC}_{50}$ değeri kompleks 6 için $1.4 \mu \mathrm{M}$, kompleks 7 için $5.0 \mu \mathrm{M}$, cisplatin için $3.7 \mu \mathrm{M}$ olarak bulunmuştur.<smiles>CCCCCN1C=CN(C)C1[P+](Cl)(Cl)(Cl)(Cl)n1cccc1</smiles>

6

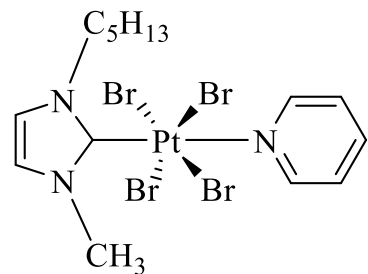

7

Rehm ve arkadaşları, 8a-e, 9a-b, 10 ve $\mathbf{1 1}$ kompleksleri kullanarak yedi insan kanser hücre dizisine karşı sitotoksisite çalışması yapmışlardır [44]. Tüm kompleksler cis-platine dirençli HT-29 [45] ve yüksek ilaç-dirençli KB-V1 / Vbl serviks [46] karsinom hücre ağına karşı düşük $\mathrm{IC}_{50}$ değerleri ile dikkate değer etkinlik göstermiştir. Rehm ve arkadaşları, bu çalışmalarında in vitro DNA etkileşimi deneyi ile cis/trans-NHC-Pt komplekslerinin DNA etkileşimi, Elektroforetik Mobilite Kaydırma Deneyi (EMSA) ile incelenmiştir. Trans-[PtII $\left.(\mathrm{NHC})_{2} \mathrm{Cl}_{2}\right] 10$ kompleksi DNA ile etkileşime girmezken, cis izomeri 8b kompleksi DNA ile etkileşime girmiştir. Bununla beraber cis izomeri $\mathbf{9 b}$ kompleksi için daha büyük bir etki gözlenmiştir. 


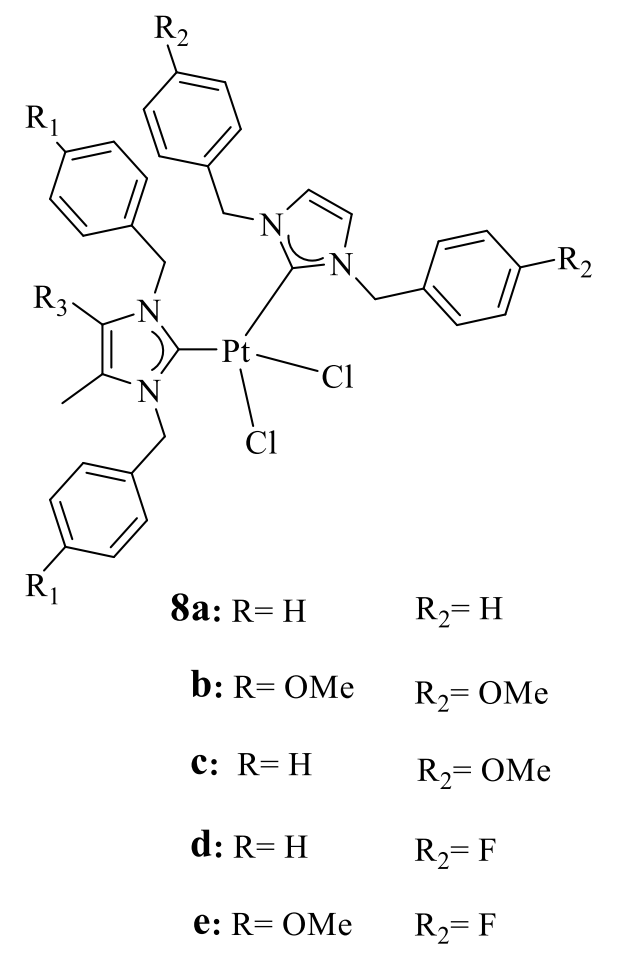<smiles></smiles>

10<smiles>[R]c1ccc(Cn2cc[n+](Cc3ccc([R])cc3)c2[P+](Cl)(c2ccc([R])cc2)n2cc[n+](Cc3ccc([R])cc3)c2-c2ccc([R])cc2)cc1</smiles>

9a: $\mathrm{R}=\mathrm{H}$

b: $\mathrm{R}=\mathrm{OMe}$<smiles></smiles>

11

Chekkat ve arkadaşları, in vitro ve in vivo deneylerde güçlü antitümör etkinliğine sahip NHCpolietilenimin platin kompleksleri sentezlemişlerdir. Katyonik kompleksler 12b ve 12c'nin tamamen inaktif olduğu bulunmasına karşın, etanol amin ligandı içeren 12a nötr platin-NHC kompleksi sitotoksik aktivite göstermiş̧ir. Sentezlenen komplekslerden özellikle polimer kompleks 12PEI U87, HCT116, PC3, 3T3 ve TCI hücre ağları üzerinde etkili olmuştur. İn vitro çalışmada, sentezlenen 12PEI kompleksinin HCT116 hücre ağ 1 üzerinde $\left(\mathbf{1 2 P E I} \mathbf{I}_{10}\right.$ için $\mathrm{IC}_{50} \approx 21 \mu \mathrm{M}, \mathbf{1 2 P E I}_{20}$ için $\mathrm{IC}_{50} \approx 7 \mu \mathrm{M}$ ve 12PEI 30 için $\mathrm{IC}_{50} \sim 3 \mu \mathrm{M}$ ) etkili olduğu bulunmuştur. Komplekslerin DNA üzerinde oksidatif stresi arttırdığı ve mitekondride ROT üreterek apoptozu stimüle ettiği saptanmıştır [47]. 
<smiles>CN1C=CN(Cc2ccccc2)C1[I+](N)(I)I</smiles>

$12 \mathrm{a}$<smiles>CN1C=CN(Cc2ccccc2)C1[PH](C)(I)CCI</smiles>

$12 b$<smiles>CN1C=CN(Cc2ccccc2)C1[PH](I)(I)CNCCN</smiles>

$12 \mathrm{c}$<smiles>CCCNC(C)CNCCN</smiles>

$12_{\text {PEI }}$

\subsection{2. $\mathrm{Cu}-\mathrm{NHC}$ kompleksleri}

Bakır elementi Pt ile karşılaştırıldığında hücre metabolizması açısından daha az toksik ve oldukça önemli rollere sahiptir [34, 48-50]. Çünkü $\mathrm{Cu}$ elementi birçok enzimin kofaktörüdür. Dolayısıyla $\mathrm{Cu}$ elementi biyolojik özellikleri ile medikal alanda yoğun uygulama alanı bulmuştur [34, 36, 48, 51-53]. $\mathrm{Cu}-\mathrm{NHC}$ kompleklerinin antikanser özellikleri Pt-NHC kompleklerinden farklıdır. Özellikle Cu-NHC bileşiklerinin redoks döngüsü ve ROT oluşturma mekanizmaları ön plandadır [52].

Gautier ve Morel grupları tarafından geliştirilen $\mathrm{Cu}(\mathrm{I})-\mathrm{NHC}$ kompleksleri 13 ve $\mathbf{1 4}$ (Şekil 2.14.) insan kanser hücrelerine karşı yüksek sitotoksisite göstermişlerdir [54].

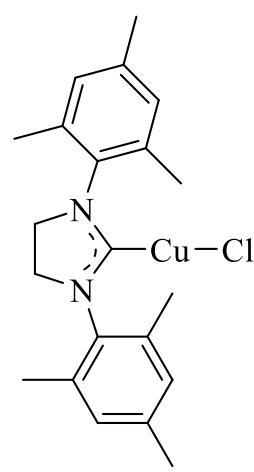

13

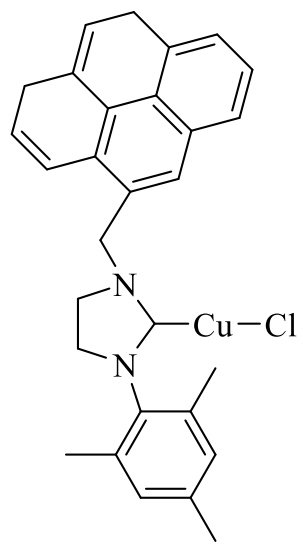

14

Bakır ile ilgili yapılan diğer bir çalışmada $\mathrm{Cu}(\mathrm{I})$-NHC kompleksleri 15 ve $16 \mathrm{ROT}$ aracılığı ile kanser hücreleri üzerinde güçlü sitotoksisite gösterdiği saptanmıştır [37, 55, 56]. 
<smiles>CCC1=[N+](c2c(C)cccc2C)CCN1c1c(C)cccc1C</smiles>

15<smiles>CCN(CC)C(=O)Cn1cc[n+](CC(=O)N(CC)CC)c1Cl</smiles>

16

Bertrand ve arkadaşları, asiklik karben ligantları ile $\mathrm{Cu}-\mathrm{NHC}$ kompleksleri sentezlemişlerdir. Bu bakır kompleksleri 17, 18 ve 19 düşük submikromolar aralıkta $\mathrm{IC}_{50}$ değerleri ile ve MCF-7'ye karş1 yüksek aktivite göstermişlerdir. Tipik olarak yüksek cis-platin direncini gösteren bir hücre dizisi olan A549'a karşı $\mathrm{IC}_{50}$ değerleri de cis-platinden daha düşük çıkmıştır [57].

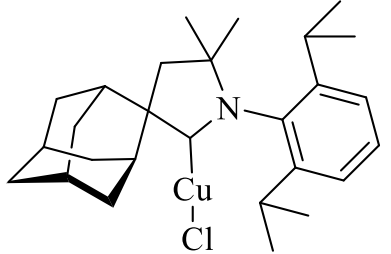

17

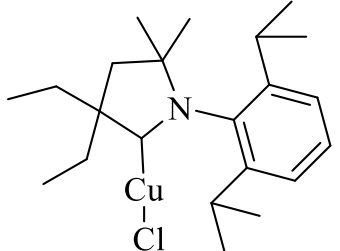

18<smiles>CCc1cccc(C(C)(C)C)c1N1C(Cl)C(C)(C)CC1(C)C</smiles>

19

Streciwik ve ark. çalışmalarında, $\mathrm{Cu}(\mathrm{I}) \mathrm{NHC}$ kompleksleri 20 mikromolar ve submikromolar aralıkta düşük $\mathrm{IC}_{50}$ değerleri ile MCF-7 ve Caki-1 hücrelerine karşı yüksek sitotoksisite gösterdiklerini tespit etmişlerdir [58]. Özellikle MCF-7 hücrelerine karşı $0.60 \mu \mathrm{M}^{\prime} \mathrm{l}_{1 \mathrm{k}} \mathrm{IC}_{50}$ değeri ve Caki-1 hücrelerine karş1 $0.65 \mu \mathrm{M}^{\prime}$ lık $\mathrm{IC}_{50}$ değerine sahip olan $\mathrm{Cu}(\mathrm{I}) \mathrm{NHC}$ kompleksi 20, umut verici sonuçlar sergilediğinden daha ileri biyolojik çalışmalar için seçilmiştir [59]. Bu Cu(I)NHC kompleksi 20, in vitro olarak NCI60 kanser hücresi panelinde test edildi ve 288 nM'lik bir ortalama GI $_{50}$ değeri sergileyen, renal hücreli kanser hücreleri de dahil olmak üzere çok çeşitli insan kanser hücrelerine karşı çok iyi aktivite göstermiştir. Caki-1 tümör taşıyan farelerde, maksimum tolere edilebilir doz deneylerinde düşük dozda (5 mg / kg), toksik olmayan ölümlerle hafif ve tersinir vücut ağırlığı kaybına neden olmuştur.<smiles></smiles>

20<smiles>O=[N+]([O-])c1ccc(Cc2ncn(Cc3ccc([N+](=O)[O-])cc3)c2CBr)cc1</smiles>

21

$\mathrm{Cu}(\mathrm{I}) \mathrm{NHC}$ kompleksi 21, Pellei ve ark. tarafindan cis-platin'e duyarlı ve dirençli hücreler dahil olmak üzere çeşitli insan kanser hücrelerinde sitotoksik özellik açısından geliştirildi ve değerlendirildi [60]. $\mathrm{Cu}(\mathrm{I}) \mathrm{NHC}$ kompleksi 21, insan A431 servikal, A549 akciğer, HCT-15 kolon ve BxPC3 pankreatik kanser hücrelerine karşı cis-platinden yaklaşık 3-7 kat daha etkili olmuştur. Ayrıca test edilen tüm 
kanser hücre ağlarına karşı eşdeğer M-NHC kompleksleri (Ag-NHC ve Au-NHC) ile karşılaştırıldığında en sitotoksik türev olarak ortaya çıkmıştır.

\subsection{M-NHC'lerin antikanser etki mekanizmaları}

M-NHC'lerin antikanser ajanı olarak kullanılmasında farklı etki mekanizmaları ortaya konmuştur. $\mathrm{Bu}$ etki mekanizmaları DNA mutasyonları ve Reaktif Oksijen Türevleri (ROT) üretimidir.

\subsubsection{DNA mutasyonları}

DNA molekülü metal temelli ilaçların ilk hedef noktası olarak düşünülmektedir. Bunun en önemli örneğini platin temelli ilaçlar oluşturmaktadır [57]. Bu nedenle metal temelli yeni ilaçlar tasarlarken en önemli parametrelerden biri DNA ile etkileşime girmesi ve mutasyonlar meydana getirmesidir. Bu ilaçların yapısının çeşitlendirilmesi ve etkinliğinin artırılmasında, DNA ile etkileşimin yanında, hidrojen bağı oluşturabilmeleri ve aren halkasının açılmasını başlatacak hidrofobik etkileşimler yapabilmeleri de önemlidir.

DNA'ya bağlanma türüne göre ilaçlar iki tip olarak sınıflandırılırlar. Bunlardan birincisi koordinasyon bağlanması olup genellikle DNA'nın oyuklarına bağlanan, DNA zincirleri arasında şelat oluşturan ve DNA sarmalında yer alan fosfodiester köprüsüne bağlanan ajanlardır. İkinci sınıf ise koordinasyon bağlanması içermeyip elektrostatik etkileşimleri kapsamaktadır. Son zamanlarda yapılan çalışmalarda Pt komplekslerinin etki mekanizmasının DNA'nın çift sarmal heliks yapısı ile etkileşime girmeleri olduğu rapor edilmiştir. Şekil 2.'de Pt komplekslerinin en sık şekilde DNA üzerinde bağlandığ 1-2,Guanin-Guanin (1,2-GG) ve 1-2, Adenin-Guanin (1,2-AG) bölgelerini göstermektedir. Bu aynı zamanda birçok metal temelli antikanser ilaçları içinde muhtemel bağlanma noktasını temsil etmektedir [61].

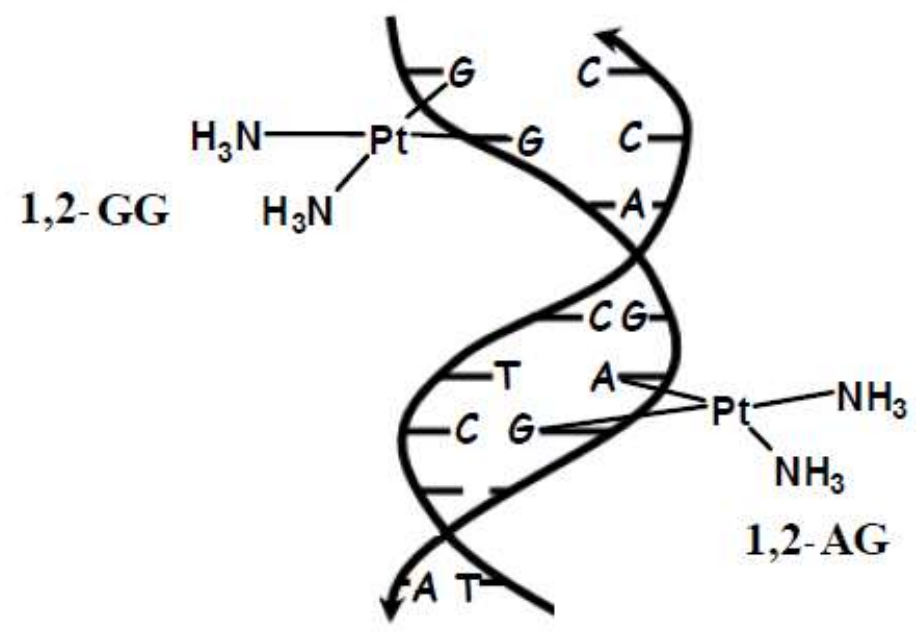

Şekil 2. DNA çift sarmal heliks yapısına Pt-komplekslerinin muhtemel bağlanma noktaları

Özellikle guanin bazının 7. pozisyonundaki N (azot) atomu en muhtemel hedeftir. Metal merkezli antikanser ajanların DNA'ya bu şekilde bağlanarak oluşturdukları hasarlı DNA hücre bölünmesini inhibe ederek kanser hücrelerinin çoğalmasını engellemektedir [61].

\subsubsection{Reaktif oksijen türleri (ROT) üretimi}

Oksijenden oluşan radikaller, biyolojik sistemlerdeki en önemli serbest radikallerdir. Süper oksit anyonu, nitrik oksit, hidroksil radikali, lipid peroksit, hidrojen peroksit bilinen ROT'lerdir. ROT hücredeki hayati role sahip DNA, protein, lipidler gibi moleküllere saldırarak hücrede hasar oluşturur. Özellikle DNA molekülünde oksidasyon ile oluşan hasar sonucu hücre bölünmesi durdurularak apoptozis mekanizmaları etkin hale getirilir ve hücre ölüme gönderilir. Bu konuda yapılan çalışmalar 
ile M-NHC bileşiklerinin hücrelerde ROT üretimini arttırarak kanser hücreleri üzerinde etkili olduğu ortaya konulmuştur. Özellikle $\mathrm{Cu}-\mathrm{NHC}$ bileşiklerinin redoks döngüsü ve ROT oluşturma mekanizmalarını oldukça aktif olarak kullandıkları rapor edilmiştir [62]. Ayrıca oluşan serbest radikallerinin hücrede önemli görevlere sahip protein tiroksin fosfataz enzimlerin aktivitesini inhibe ederek hücrenin redoks döngüsü ve metabolik regülasyonunu bozduğu rapor edilmiş olup bu özelliklerin de antikanser aktivitede etkili olduğu düşünülmektedir $[37,55,56]$.

\section{Sonuç ve Öneriler}

M-NHC kompleksleri, katalizör özellikleri iyi bilinen bileşikler olup son yıllarda biyolojik özellikleri ile ön plana çıkmaktadır. Son 10 yılda bu biyolojik özelliklerden antikanser özellikleri yoğun ilgi görmektedir. Literatürde antikanser özellik sergileyen bileşiklerin sentezi ve uygulamasını içeren birçok çalışma mevcuttur. Yapılan çalışmalarda metal olarak Pt ve $\mathrm{Cu}$ yaygın kullanım alanına sahiptir. $\mathrm{Bu}$ bileşiklerin antikanser etki mekanizmaları, tam olarak bilinmemekle beraber özellikle DNA mutasyonları ve ROT üretimi artışı ile hücrede oksidasyon olaylarının artması gösterilmektedir. Bununla beraber bu bileşiklerin antikanser etki mekanizmasını ortaya koyacak ve yeni sentez çalışmalarına yol gösterecek çalışmaların yapılmasının gerekliliği de açıktır.

\section{Kaynaklar}

[1] Öfele K. 1968. 1,3-Dimethyl-4-imidazolinyliden-(2)-pentacarbonylchrom ein neuer Übergangsmetall-carben-komplex. Journal Organometallic Chemistry, 12: 42-43.

[2] Matzingerand S., Fulscher M.P. 1995. Methyl substitution in carbenes. A theoretica prediction of the singlet-triplet energy separation of dimethylcarbene. Journal of Physical Chemistry, 99 (27): 10747-10751

[3] Wanzlick H.W., Schönherr H.J. 1968. Direct Synthesis of a Mercury Salt-Carbene Complex. Angewandte Chemie International Edition, 7 (2): 141-142.

[4] Arduengo III A.J., Harlow R.L., Kline M. 1991. A Stable Crystalline Carbene. Journal of the American Chemical society,113(1): 361-363.

[5] Sarı Y., Aktaş A., Barut Celepci D., Gök Y., Aygün M. 2017. Synthesis, Characterization and Crystal Structure of New 2-Morpholinoethyl-Substituted Bis-(NHC)Pd(II) Complexes and the Catalytic Activity in the Direct Arylation Reaction. Catalysis Letter, 147 (9): 2340-2351.

[6] Gök Y., Aktaş A., Erdoğan H., Sarı Y. 2018. New 4-vinylbenzyl-substituted bis(NHC)-Pd(II) complexes: Synthesis, characterization and the catalytic activity in the direct arylation reaction. Inorganica Chimica Acta, 471: 735-740.

[7] Erdoğan H., Aktaş A., Gök Y., Sar1 Y. 2018. N-Propylphthalimide-substituted bis-(NHC)PdX2 complexes: synthesis, characterization and catalytic activity in direct arylation reactions. Transition Metal Chemistry, 43 (1): 31-37.

[8] Aktaş A., Akkoç S., Gök Y. 2013. Palladium catalyzed Mizoroki-Heck and Suzuki-Miyaura reactions using naphthalenomethyl-substituted imidazolidin-2-ylidene ligands in aqueous media. Journal of Coordination Chemistry, 66 (16): 2901-2909.

[9] Haque R.A., Choo S.Y., Budagumpi S., Iqbal M.A., Abdullah A.A. 2015. Silver(I) complexes of mono- and bidentate N-heterocyclic carbene ligands: Synthesis, crystal structures, and in vitro antibacterial and anticancer studies. European Journal of Medicinal Chemistry, 90: 82-92.

[10] Li Y., Tan C.-P., Zhang W., He L., Ji L.-N., Mao Z.-W. 2015. Phosphorescent iridium(III)-bis$\mathrm{N}$-heterocyclic carbene complexes as mitochondria-targeted theranostic and photodynamic anticancer agents. Biomaterials 39: 95-104.

[11] Nguyen M.T., Nguyenand T.L., Le H.T. 1999. Theoretical Study of Dithioformic Acid, Dithiohydroxy Carbene and Their Radica Cations: Unimolecularand Assisted Rearrangements. The Journal of Physical Chemistry A, 103 (29): 5758-5765.

[12] Kühl O. 2010. Functionalised N-Heterocyclic Carbene Complexes. John Wiley\&Sons, 7-8.

[13] Kühl O. 2009. Sterically induced differences in N-heterocyclic carbene transition metal complexes. Coordination Chemistry Reviews, 253 (21-22): 2481-2492. 
[14] Cisnetti F., Gautier A. 2013. Metal/N-Heterocyclic Carbene Complexes: Opportunities for the Development of Anticancer Metallodrugs. Angewandte Chemie International Edition, 52 (46): 11976-11978.

[15] Aktaş A., Keleştemur Ü., Gök Y., Balcıŏlu S., Ateş B., Aygün M. 2017. Synthesis, characterization, crystal structure, and antimicrobial studies of 2-morpholinoethyl-substituted benzimidazolium salts and their silver(I)-N-heterocyclic carbene complexes. Research on Chemical Intermediates, 43 (11): 6379-6393.

[16] Savić N.D., Glišić B.Đ., Wadepohl H., Pavic A., Senerovic L., Nikodinovic-Runic J., Djurana M.I. 2016. Silver(I) complexes with quinazoline and phthalazine: synthesis, structural characterization and evaluation of biological activities. Medicinal Chemistry Communication, 7 : 282-291.

[17] Krishnamoorthy P., Sathyadevi P., Butorac R.R., Cowley A.H., Bhuvanesh N.S.P., Dharmaraj N. 2012. Copper(I) and nickel(II) complexes with 1 [thin space (1/6-em)]:[thin space (1/6-em)]1 vs. 1[thin space (1/6-em)]:[thin space (1/6-em)] 2 coordination of ferrocenyl hydrazone ligands: Do the geometry and composition of complexes affect DNA binding/cleavage, protein binding, antioxidant and cytotoxic activities, Dalton Transactions, 41: 4423-4436.

[18] Li Y., Liu G.-F., Tan C.-P., Ji L.-N., Mao Z.-W. 2014. Antitumor properties and mechanisms of mitochondria-targeted $\mathrm{Ag}(\mathrm{I})$ and $\mathrm{Au}(\mathrm{I})$ complexes containing $\mathrm{N}$-heterocyclic carbenes derived from cyclophanes. Metallomics, 6: 1460-1468.

[19] Çetinkaya B., Özdemir İ., Binbaştoğlu B., Günal S. 1999. Antibacterial and Antifungal Activities of Complexes of Ruthenium (II). Arzneimitteforschung, 49 (6): 538-540.

[20] Aktaş A., Taslimi P., Gülçin İ., Gök Y. 2017. Novel NHC Precursors: Synthesis, Characterization, and Carbonic Anhydrase and Acetylcholinesterase Inhibitory Properties. Archiv der Pharmazie, 350, DOI:10.1002/ardp.201700045.

[21] Sarı Y., Aktaş A., Taslimi P., Gök Y., Gülçin İ. 2017. Novel N-propylphthalimide and 4vinylbenzyl-substituted benzimidazole salts: Synthesis, characterization, and determination of their metal chelating effects and inhibition profiles against acetylcholinesterase and carbonic anhydrase enzymes. Journal of Biochemical and Molecular Toxicology, doi.org/10.1002/jbt.22009.

[22] Erdemir F., Barut Celepci D., Aktaş A., Taslimi P., Gök Y., Karabıyık H., Gülçin İ. 2018. 2Hydroxyethyl substituted NHC precursors: Synthesis, characterization, crystal structure and carbonic anhydrase, $\alpha$-glycosidase, butyrylcholinesterase, and acetylcholinesterase inhibitory properties. Journal of Molecular Structure 1155: 797-806.

[23] Türker F., Barut Celepci D., Aktaş A., Taslimi P., Gök Y., Aygün M., Gülçin İ. 2018. metacyanobenzyl substituted benzimidazolium salts: Synthesis, characterization, crystal structure and carbonic anhydrase, $\alpha$-glycosidase, butyrylcholinesterase, and acetylcholinesterase inhibitory properties. Archiv der Pharmazie, doi.org/10.1002/ardp.201800029.

[24] Behçet A., Çağlılar T., Barut Celepci D., Aktaş A., Taslimi P., Gök Y., Aygün M., Kaya R., Gülçin İ. 2018. Synthesis, characterization and crystal structure of 2-(4-hydroxyphenyl)ethyl and 2-(4-nitrophenyl)ethyl Substituted Benzimidazole Bromide Salts: Their inhibitory properties against carbonic anhydrase and acetylcholinesterase. Journal of Molecular Structure, 1170: 160169.

[25] Rosenberg B., VanCamp L., Krigas T. 1965. Inhibition of Cell Division in Escherichia coli by Electrolysis Products from a Platinum Electrode. Nature, 205: 698-699.

[26] Ott I., Gust R. 2007. Preclinical and Clinical Studies on the Use of Platinum Complexes for Breast Cancer Treatment. Anti-Cancer Agents in Medicinal Chemistry, 7 (16): 95-110.

[27] Gust R., Beck W., Jaouen G., Schönenberger H. 2009. Optimization of cisplatin for the treatment of hormone-dependent tumoral diseases: Part 2: Use of non-steroidal ligands. Coordination Chemistry Reviews, 253 (21-22): 2760-2779.

[28] Berners-Price S.J. 2011. Activating Platinum Anticancer Complexes with Visible Light. Angewandte Chemie International Edition, 50 (4): 804-805.

[29] Wedlock L.E., Berners-Price S.J. 2011. Recent Advances in Mapping the Sub-cellular Distribution of Metal-Based Anticancer Drugs. Australian Journal of Chemistry, 64 (6): 692-704.

[30] Wheate N.J., Walker S., Craig G.E., Oun R. 2010. The status of platinum anticancer drugs in the clinic and in clinical trials. Dalton Transactions, 39: 8113-8127. 
[31] Monneret C. 2011. Platinum anticancer drugs. From serendipity to rational design. Annales Pharmaceutiques Françaises, 69 (6): 286-295.

[32] Rabik C.A. Dolan ME. 2007. Molecular mechanisms of resistance and toxicity associated with platinating agents. Cancer Treatment Reviews, 33 (1): 9-23.

[33] Gust R., Beck W., Jaouen G., Schönenberger H. 2009. Optimization of cisplatin for the treatment of hormone dependent tumoral diseases: Part 1: Use of steroidal ligands. Coordination Chemistry Reviews, 253 (21-22): 2742-2759.

[34] Tan S.J. Yan Y.K., Lee P.P., Lim K.H. 2010. Copper, gold and silver compounds as potential new anti-tumor metallodrugs. Future Medicinal Chemistry, 2 (10): 1591-1608.

[35] Scott L.E., Orvig C. 2009. Medicinal Inorganic Chemistry Approaches to Passivation and Removal of Aberrant Metal Ions in Disease. Chemical Reviewes, 109 (10): 4885-4910.

[36] Hindi K.M., Panzner M.J., Tessier C.A., Cannon C.L., Youngs W.J. 2009. The Medicinal Applications of Imidazolium Carbene-Metal Complexes. Chem. Rev., 109 (8): 3859-3884.

[37] Gautier A., Cisnetti F. 2012. Advances in metal-carbene complexes as potent anti-cancer agents. Metallomics, 4: 23-32.

[38] Mercs L., Albrecht M. 2010. Beyond catalysis: N-heterocyclic carbene complexes as components for medicinal, luminescent, and functional materials applications. Chemical Society Reviews, 39 (6): 1903-1912.

[39] Liu W., Gust R. 2013. Metal N-heterocyclic carbene complexes as potential antitumor metallodrugs. Chemical Society Reviews, 42 (2): 755-773.

[40] Alves G., Morel L., El-Ghozzi M., Avignant D., Legeret B., Nauton L., Cisnetti F., Gautier A. 2011. A platinum Chugaev carbene complex as a potent anticancer agent. Chemical Communications, 47 (27): 7830-7832.

[41] Sun R.W.-Y., Chow A.L.-F., Li X.-H., Yan J.J., Chui S.S.-Y., Che C.-M. 2011. Luminescent cyclometalated platinum(II) complexes containing N-heterocyclic carbene ligands with potent in vitro and in vivo anti-cancer properties accumulate in cytoplasmic structures of cancer cells, Chemical Science, 2: 728-736.

[42] Bouché M., Dahm G., Wantz M., Fournel S., Acharda T., Bellemin-Laponnaz S. 2016. Platinum(IV) N-heterocyclic carbene complexes: their synthesis, characterisation and cytotoxic activity. Dalton Transactions, 45 (28): 11362-11368.

[43] Ramiro-Cortés Y., Guemez-Gamboa A., Morán J. 2011. Reactive oxygen species participate in the p38-mediated apoptosis induced by potassium deprivation and staurosporine in cerebellar granule neurons. International Journal of Biochemistry \& Cell Biology, 43 (9): 1373-1382.

[44] Rehm T., Rothemund M., Muenzner J.K., Noor A., Kempe R., Schobert R. 2016 Dalton Trans., 45: $15390-15398$

[45] Sergent C., Franco N., Chapusot C., Lizard-Nacol S., Isambert N., Correia M., Chauffert B. 2002. Human colon cancer cells surviving high doses of cisplatin or oxaliplatin in vitro are not defective in DNA mismatch repair proteins. Cancer Chemotherapy and Pharmacology, 49 (6): 445-452.

[46] Shen D.-W., Cardarelli Hwang C.J., Cornwell M., Richert N., Ishii S., Pastan I., Gottesman M.M. 1986. Multiple drug-resistant human KB carcinoma cells independently selected for high-level resistance to colchicine, adriamycin, or vinblastine show changes in expression of specific proteins. Journal of Biological Chemistry, 261: 7762-7770.

[47] Chekkat N., Dahm G., Chardon E., Wantz M., Sitz J., Decossas M., Lambert O., Frisch B., Rubbiani R., Gasser G., Guichard G., Fournel S., Bellemin-Laponnaz S. 2016. N-Heterocyclic Carbene-Polyethylenimine Platinum Complexes with Potent in Vitro and in Vivo Antitumor Efficacy. Bioconjugate Chemistry, 27 (8): 1942-194.

[48] Tisato F., Marzano C., Porchia M., Pellei M., Santini C. 2010. Copper in diseases and treatments, and copper-based anticancer strategies. Medicinal Research Reviews, 30 (4): 708-749.

[49] Wang T., Guo Z. 2006. Copper in Medicine: Homeostasis, Chelation Therapy and Antitumor Drug Design. Current Medicinal Chemistry, 13 (5): 525-537.

[50] Marzano C., Pellei M., Tisato F., Santini C. 2009. Anti-Cancer Agents. Medicinal Chemistry, 9 (2): 185-211.

[51] Teyssot M.L., Jarrousse A.S., Chevry A., De Haze A., Beaudoin C., Manin M., Nolan S.P., DiezGonzalez S., Morel L., Gautier A. 2009. Toxicity of Copper(I)-NHC Complexes Against Human 
Tumor Cells: Induction of Cell Cycle Arrest, Apoptosis, and DNA Cleavage. Chemistry A European Journal, 15 (2): 314-318.

[52] Ruiz-Azuara L., Bravo-Gomez M.E. 2010. Copper Compounds in Cancer Chemotherapy. Current Medicinal Chemistry, 17 (31): 3606-3615.

[53] Bowen R.J., Navarro M., Shearwood A.M., Healy P.C., Skelton B.W., Filipovska A., BernersPrice S.J. 2009. 1:2 Adducts of copper(I) halides with 1,2-bis(di-2-pyridylphosphino)ethane: solid state and solution structural studies and antitumour activity. Dalton Transactions, 2009 (48): 10861-10870.

[54] Teyssot M.L., Jarrousse A.S., Manin M., Chevry A., Roche S., Norre F., Beaudoin C., Morel L., Boyer D., Mahiou R., Gautier A. 2009. Metal-NHC complexes: a survey of anti-cancer properties. Dalton Transactions, 2009 (35): 6894-6902.

[55] Pellei M., Gandin V., Marinelli M., Marzano C., Yousufuddin M., Dias H.V.R., Santini C. 2012. Synthesis and Biological Activity of Ester- and Amide-Functionalized Imidazolium Salts and Related Water-Soluble Coinage Metal N-Heterocyclic Carbene Complexes. Inorganic Chemistry, 51 (12): 9873-9882.

[56] Yang P., Guo M. 1999. Interactions of organometallic anticancer agents with nucleotides and DNA. Coordination Chemistry Reviews, 185-186: 189-211.

[57] Bertrand B., Romanov A.S., Brooks M., Davis J., Schmidt C., Ott I., O’Connell M., Bochmann M. 2017. Synthesis, structure and cytotoxicity of cyclic (alkyl)(amino) carbene and acyclic carbene complexes of group 11 metals. Dalton Transactions, 46: 15875-15887.

[58] Streciwilk W., Hackenberg F., Muller-Bunz H., Tacke M. 2014. Synthesis and cytotoxicity studies of p-benzyl substituted NHC-copper(I) bromide derivatives. Polyhedron, 80: 3-9.

[59] Walther W., Fichtner I., Hackenberg F., Streciwilk W., Tacke M. 2014. In Vitro and In Vivo Investigations into the Carbene Gold Chloride and Thioglucoside Anticancer Drug Candidates NHC-AuCl and NHC-AuSR. Letters in Drug Design \& Discovery, 11 (2):825-832.

[60] Pellei M., Gandin V., Marinelli M., Orsetti A., Del Bello F., Santini C., Marzano C. 2015. Novel triazolium based 11th group NHCs: synthesis, characterization and cellular response mechanisms. Dalton Transactions, 44: 21041-21052.

[61] Pizarro A.M., Sadler P.J. 2009. Unusual DNA binding modes for metal anticancer complexes. Biochimie, 91 (10): 1198-1211.

[62] Ehrenfeld G.M., Shipley J.B., Heimbrook D.C., Sugiyama H., Long E.C., Van B.J.H., Van M.G.A., Oppenheimer N.J., Hecht S.M. 1987. Copper-Dependent Cleavage of DNA by Bleomycin. Biochemistry, 26: 931-942. 